sarca generally more prominent in the upper, than in the lower, parts of the body. He says, that until now he scarcely knows what it is to be ill; that at, and since, the fall of the leaf he has had a troublesome eruption to which he had been many years occasionally subject; as it lasted longer than usual, be was advised by an old woman to drink his own urine for nine days, taking early in the morning, on a fasting stomach, precisely the whole quantity voided on going to bed; says that he got through the nine doses, but thinks he began to swell before he had finished the course; he has fluid in the abdomen, and in the parietesofichest and belly, swelling, how ever, greatest in the upper parts; the urine is scanty, thick, deep brown, and very offensive; he has a heaviness of the head, increased on stooping, and his own words are, that he feels too heavy for work, having neither his usual warmth nor life in him; he has little thirst; his pulse is under 90 ; his countenance pale, and its expression heavy and rague; he walks with a stick because, he says, he feels the want of support; he has not been un usually exposed to cold or to wet, and is of temperate habits; the urine is not albuminous; he loses his breath if he walks quick, and is obliged to stop. Deeming this case to be due to the poisonous impression, or to the ingestion of the urine by endosmosis into the circulation, $I$ ordered a smart purgative of calomel and colocynth, and afterwards six pills of calomel, squill, and digitalis, with heath-broom tea. The water was all dispersed, and the man back to his work within ten days; he required no repetition of the medicine; the urine did not pass as it was used to do before this illness, till the ninth day.

Nearly eight years have elapsed and this man has never since been ill a single hour. He still works on the road at Turnham-green, and is known as a steady industrious labourer; he now lives in Fisher's-lane. I shall not pronounce whether this dropsy ought to be referred to the ingestion of the urine merely, or to the damage done to the imnervation by its contact with the tissues. The late Dr. Fox, of Plymouth, has recorded a series of cases of anasarca, produced by part of the crew of a vessel liiding themselves from a press-gang, by allowing themselves to be buried in salt; the bite of the rattlesnake will produce dropsy; so will that of the viper; and so will bad unwholesome food. I have known a single debauch as the last link to produce the same effect.

32 , Spring-gardens,

\section{ON THE TREATMENT OF PLACENTA PRAVIA}

\section{By R. Forester Wexts, Esq., M. R. C.S. Eng., London.}

The following case was brought under my notice a few days since by a medical friend; and as the treatment of placenta pravia is now a "questio vexata," a report of it may be interesting to the readers of Trr LANCET, since it will form an additional link in the chain of evidence upou which all medical practice must depend.

Margaret $\mathrm{C}$ - aged thirty-six, a sickly-looking Irishwoman, at the begirning of last May, then about the fourth month of her eleventh pregnancy, was attacked with uterine hamorrhage which continued, with very little remission, until the middle of June, and then left her in a very prostrate state. At ten o'clock A.M. of Friday last, the liquor amnii was spontaneously discharged, without the occurrence of any pain; and at three o'clock A.M. of the following day, she was seized with hæmorrhage to a very alarming extent; at four o'clock I was requested to see her. She was in the usual obstetric position; the surface of the body cold and clammy; the complexion sallow; the lips and tongue quite blanched ; the pulse at the wrist scarcely perceptible and very rapid; and the voice scarcely audible. Upon examination, I found the vagina filled with coagula, the os uteri dilated to about the size of a halfcrown piece, and, notwithstanding the hæmorrhage, rather rigid, and the placenta implanted centrically over it. Considering this a case in point, I determined to put in practice the plan of separation recommended by Dr. Simpson; I passed two fingers between the placenta and cervix, and with some difficulty separated it completely all roind, and at the same time ascertained that an arm was the presenting part: as there was no pain, and the uterus appeared in a perfectly inert state. 3 ss of the ergot was administered in brandy, and cold was applied to the vulva. Upon examining at the end of an hour, there had been no return of the bleeding; the os uteri was in the same rigid state, but the placenta had been forced lower down, and protruded somewhat inio the ragina, there being no pain, and it still being impossible to turn the child, $3 \mathrm{ss}$ of the ergot was administered every hour until four doses had been taken. On seeing her again at nine o'clock, the ergot not having produced any effeet, a fourth part of an in- fusion of $3 \mathrm{iij}$, with dilute sulph. ac., was administered every two hours. At two o'clock P.Mr., pains having recurred, as I was out of the way, the gentleman who had the charge of the case attended, and found the placenta in the ragina, and a leg and arm descending: the leg was brought down, and the delivery speedily accomplished, the placenta immediately following the head. The child, a male of about eight months, uterine age, had apparently been dead some days; the patient is progressing satisfactorily, although it must be some months before she recovers from the effects of this excesssive bleeding. The usual practice in such cases has been to turn, but here that was utterly impossible from the state of the os uteri, and yet ten hours elapsed from this most alarming attack of hæmorrhage, and the period when that operation could be performed with safety; the consequences to this poor creature could not have been otherwise than fatal, had that been waited for, and that, too, in all probability, previous to the delivery.

I have met with six other cases of placenta prævia; three of them complete, and three partial. In one of the complete cases the woman died a few minutes after the performance of artificial evolution; and in a second, about ten days after delivery ; the third was successful to the mother. Two of the three children were dead. In the three partial cases rupture of the membranes stopped the bleeding; in one case craniotomy was subsequently performed on account of deficiency of space in superior aperture of pelvis, and the woman had a protracted recovery after phlegmasia dolens; the other two women did well; all the children were dead. I have another case in my note-book-but I cannot so well authenticate it-where the woman was seized with flooding at the sixth month of pregnancy, and expelled the contents of the uterus en masse; I was not present until half an hour after the birth; but a woman of experience in such matters, who had assisted her, told me the placenta came first.

Unavoidable hæmorrhage is unquestionably the most formidable complication with which the accoucheur has to grapple, and artificial evolution is by no means an easy operation to perform. I am convinced that the great bulk of the profession will feel indebted to Dr. Simpson for having suggested this additional means of treating these alarming cases; and I have no doubt, from the comparative ease with which it may be performed in most cases, that it will almost supersede the old method. Although the child's life is inevitably sacrificed, yet the numerical fatality under the treatment by evolution is so great, that I think few practitioners will be disposed to risk the continuance of the hæmorrhage in order to save it: but it of course requires an accumulation of facts to establish the superiority of this, as of any other, obstetric operation.

1, Steward-street, Spital-square, Oct. 30th, 1845.

\section{CASE OF SUPPOSED MODIFIED GLANDERS IN THE} HUMAN SUBJECT, COMMUNICATED BY INOCULATION FROM A GLANDERED HORSE.

By Crrarles Poolex, Isq., Surgeon, Cirencester.

ON the 24th September, Charles $\mathrm{C}-$, aged thirty-one, a stout, well-made man, in the service of Lord Gifford, applied for advice under the following circumstances. It appears that, a week before, when engaged in cutting up a horse for the hounds, the knife slipped, and inflicted a slight scratch on his left thumb; and on the following day he killed and dismembered another horse, that was unequivocally affected with glanders, the scratch on his thumb not being then healed; the ensuing day, his thumb became a little painful and swollen, and, knowing from experience the dangerous nature of the wound, he fomented it frequently with hot water, and applied a large linseed poultice; the third day after inoculation, he was alarmed by pains shooting up his arm, and stiffness in the arm-pit, which, however, gave way to the repeated use of hot fomentations; on the fourth day, the pain slifted to the joints of the thumb, the scratch being perfectly healed; the pain thus continued to shift about to different parts of the thumb, up to the day he applied for advice. The thumb now presented a swollen appearance; was very hot and painful, and on the first joint was a circumscribed swelling about the size of a shilling, red, quite hard, and tender on being touched, gradually rising to a small obtuse cone, the top of which was indented, and marked by a yellow spot; the pain, heat, and swelling did not extend beyond the thumb, and there was no swelling in the axilla; the man's countenance was dejected, and he complained of restlessness and debility; his nights were sleepless, owing to increase of pain at that time; tongue clean, and rather dry; pulse 90, and firm; bowels regular; is thirsty, and is annoyed by a constant unpleasant taste in the moth. 
A linseed poultice was applied; and two grains of opium, A linseed poultice was applied; and two grains of opium,
along with twelve grains of compound extract of colocynth,ordered, to be divided into four pills, two of which were to be taken each night at bed-time; a draught of the compound senna mixture, the mornings following.

26th.-Medicine has acted well; has passed two restless and disturbed nights, from the incessant pain and intolerable heat in the thumb; the pain has affected the tips of all the fingers, and on the fourth finger of the left hand is the appearance of a circumscribed swelling, resembling, in every respect, that on the thumb; the swelling of the thumb has diminished a little, but it still continues hot and red; pulse 92, soft; tongue clean, and still rather dry; eyes dry-looking; urine natural; appetite capricious. Compound ipecacuanha powder, ten grains, was ordered each night, with a draught of compound decoction of cinchona, $\zeta$ vss., and compound tincture of cinchona, 3 ss., a sixth part to be taken every six hours; linseed poultice continued.

28th.--During the last two nights has slept at intervals, but was frequently awoke by wandering unpleasant dreams; during the day he is tolerably easy, but towards night the pain increases; the thumb and finger are less swelled, the heat and redness the same; tongue clean, less dry; pulse 88, soft; bowels not open; feels low-spirited and languid, and is unable to set about anything; appetite improved. Ordered to continue the poultice and the bark, and take two colocynth pills at bed-time.

30th.- The pain in the fingers was better till last night, when the fourth finger became hotter and more painful; his nights are still restless, and he is watchful; complains of headache and dizziness this morning, and of a little oppression on the chest; for several hours, yesterday evening, he suffered from considerable swelling and tenderness of the cervical and parotid glands; the swelling subsided during the night; bowels open; tongue clean, and moister; pulse 84, soft; appetite good; the thumb still exhibits some swelling and redness, with tenderness, and the finger is rather more swelled and painful than before. Ordered two colocynth and calomel pills to be taken each night; applied nitrate of silver round the thumb, at the base of the swelling, and to the fourth finger; continue the poultice.

October 3d.-The swelling of the thumb and finger have nearly subsided, and though stiff and a little painful, he is able to use them a little; sleeps well at night; bowels regular; pulse 78 , moderately full, and soft; tongue clean, expresses himself in better spirits this morning, and wishes to go to work. Ordered him to leave off the poultice, and regulate his bowels by an aperient occasionally.

I saw this man several days afterwards, and he assured me that the only inconvenience he felt in the thumb and finger was from stiffness in the joints; he looked well in face, and was living in his accustomed way.

Remarks.-I rest my opinion that the foregoing case was one of modified glanders upon two circumstances:- the character of the local symptoms, and the disposition of the glandular system generally to become affected; and this is strengthened by the knowledge that many cases are on record to warrant the belief that glanders is capable of being communicated to the human subject by inoculation. The character of the local symptoms differed from those of a simple poisoned wound, in the affection shifting its position, and in the appearance of the circumseribed swelling, which was unlike any swelling, arising from a poisoned wound, that I have ever seen ; it more resembled what is called "farcy buds" in horses. The scratch was on the end of the thumb; it was on the joint that the swelling arose; and on the sixth day, without any apparent cause, a similar "bud" showed itself on the fourth finger. The absorbents of the arm were slightly inflamed at first, and there was a little stiffness in the axilla, and on the tenth day the cervical and parotid glands were swollen and tender for some hours, evidence of the disposition of the glandular system to become affected. It has been asserted that "glanders" is always accompanied by the well-known defluxion from the nose; I am not sufficiently acquainted with the nature of the disease to say whether this assertion may be modified or not; but certainly, in this case, there was no increase of mucous secretion, nor was there any pulmonary symptom to lead to the suspicion that the mucous lining of the air-cells was at all affected, though, on the tenth day, he experienced a sense of oppression on the chest. The dry-looking conjunctiva, taken in connection with the thirst and dryish state of the tongue, evince the irritative fever that was creeping on. Notwithstanding the constant use of linseed poultices, suppuration did not take place, but the swelling gradually subsided.
FEVER, AND ITS CAUSES.

By W. Smith, Esq., F.R.C.S., \&c., Bristol.

THE antiquity of the doctrine of Broussais is evident when perusing the preface of Celsus. Erasistratus may be called the Broussais of the ancients; most strictly do his doctrines coincide with those of the modern pathologist; Celsus was more cautious, and objected to such rapid generalization:-- "Notæ vero inflammationis sunt quatuor, rubor et tumor, cum calore et dolore. Quo magis erravit Erasistratus, qui febrem nullam sine hac dixit." Again,- - Neque verum est, quod dicitur à quibusdam, nullam febrem inordinatam esse, nisi aut ex vomicâ, aut ex inflammatione, aut ex ulcere. Facilior enim semper foret curatio, si hoc verum esset. Sed quod evidentes causæ faciunt, facere etiam abditæ possunt." Celsus evidently thought that there were some "abditæ causæ," some concealed causes, which produced fever, independent of those palpable lesions, in which the gross materialism of his generation sought the cause. Thus we have the opinions of Erasistratus stated in language as lucid, and, considering our improved anatomical knowledge, with as much appearance of probability as those of recent inquirers. He taught, also, that congestion predisposed to inflammation"Erasistratus, qui transfuso in arterias sanguine febrem fieri dicit, idque nimis repleto corpore incidere."

The arteries were thought by the ancients to contain air, and the passage of blood into them explained, in their minds, both the primary flush and subsequent dark appearance in inflammation. So he observes as follows in still remarking on the opinions of Erasistratus:- "Sanguis in eas venas, quæ spiritui accommodate sunt, transfunditur, et infammationem, quam Græci 'phlegmonen' nominant, excitat ; eaque inflammatio talem motum excitat, qualis in febre est, ut Erasistrato placuit." Another piece of theory which we find recorded by the same author, strongly reminds us of the mode of accounting for inflammations which a distinguished professor of the present day adopted:- " Manantia corpuscula per invisibilia foramina subsistendo, iter claudunt; at Asclepiades contendit." In Asclepiades do not your readers recognize the Magendie of his age?

All these theories were evidently the result of that tendenoy in the human mind which snatches at the tangible, as the true, and rejects the unknown, as the unreal. If a palpable reason be not ready, one is invented; and the slightest appearance which is in approximation merely to the effect, is taken as the antecedent, to the exclusion of the million unknown causes, which human ignorance has never dreamt of.

Perhaps we may furnish some useful hints towards tracing the causation of fever, by considering the close and intimate relation of every part of the human frame to its fellow units; and, secondly, by allowing that general causes, i. e., causes affecting the whole economy are equally potential in producing that general derangement, which we denominate fever, as special lesions. Thus, to illustrate the subject, if an individual suffers a severe accident, within a short time after such has occurred, alternate shivering and heat, accelerated pulse, repressed secretions, a depressed condition of the mind, anxiety, and bodily and mental lassitude set in; these, and other symptoms, constituting fever. Again, if any organ of the human frame, or any of its tissues become inflamed-if erysipelas attack the cutis, pleuritis the pleura, or phlegmon the cellular tissue-then, fevers, that is to say, collections of the beforenamed symptoms, set in. They increase with the disease, "grow with its growth, and strengthen with its strength,"
and finally leave the debilitated frame only when the inflammation itself has passed away.

From these well established facts arose the theories of those who saw in fever but a group of symptoms, indicative of local lesion. On the other hand, it may be asserted, without fear of contradiction, that in the very cases where pyrexia has raged more fearfully than it has ever been observed to do from local inflammation or injury, very little has been detected of injured structure, or diseased organization; and that the cause which prostrated the strength, and brought the patient to the grave, has not been detected by the most patient examination.

That the proximate cause may be a general one is evident from the general implication which the symptoms exhibit.

If the circulating system, from bad food, confined atmosphere, or any other cause, becomes deranged, we get fever as a consequence.

If the nervous system receive a shock-if hope be disappointed, or sudden sorrows occur-we also frequently see fever.

If the secreting apparatus be deranged, whether by overaction, or by want of activity, the same result follows.

Want of sleep, want of food and drink-too much sleep, and 